Yüzüncü Y1 Üniversitesi
Tarim Bilimleri Dergisi

Araştırma Makalesi (Research Article)

\title{
Arapgir Dolma Biber Popülasyonundan Seleksiyonla Seçilen Ümitvar Genotiplerin Bitkisel Özellikleri Yönünden İncelenmesi
}

\author{
Özlem ALTUNTAŞ ${ }^{1}$, Rabia KÜÇÜK*2 ${ }^{2}$ Miraç DEĞİRMENCİ ${ }^{3}$
}

1,2,3 Malatya Turgut Özal Üniversitesi, Ziraat Fakültesi, Bahçe Bitkileri Bölümü, 44210, Malatya, Türkiye
${ }^{1}$ https://orcid.org/0000-0002-6508-7368 ²https://orcid.org/0000-0001-6772-7448 https://orcid.org/0000-0001-6079-3530
*Sorumlu yazar e-posta: rabia.kucuk@ozal.edu.tr

\section{Makale Bilgileri}

Geliş: 17.09 .2020

Kabul: 30.12.2020

Online Yayınlanma 30.03.2021

DOI: 10.29133 yyutbd.793803

\section{Anahtar kelimeler}

Biber (Capsicum annuum), Çeşit,

Gen kaynağ1,

Seleksiyon,

Verim.
Öz: Bu çalışma, Malatya ve çevresinde biber yetiştiriciliğinde $\% 80$ gibi yüksek bir oranda tercih edilen, yöre halkı tarafından severek tüketilen ve sebze yetiştiriciliği yapılan alanlarda en fazla yetiştirilen sebzelerden birisi olan Arapgir biberi ile gerçekleştirilmiştir. Çalışmanın amacı popülasyonun saflaştırılması, verim ve kalitesi yüksek hatları ortaya çıkararak, standart ve hibrit çeşitler geliştirmek üzere başlangıç materyali elde etmektir. Arapgir biberi'nin yoğun olarak yetiştiriciliğinin yapıldığı yörelerden tohumluk toplanmış, bu tohumlardan yetiştirilen bitkiler değerlendirilmiş olup, seçilen hatların saflaştırılması "Döl Kontrollü Teksel Seleksiyon" yöntemi ile gerçekleşmiştir. İyi özellikteki 20 hat belirlenerek, iki yılın sonunda elde edilen hatlarda verim ve bazı meyve özellikleri tespit edilmiştir. Sonuç olarak, S3 $\left(3234.3 \mathrm{~g} / \mathrm{m}^{2}\right)$, S4 $\left(2959.7 \mathrm{~g} / \mathrm{m}^{2}\right)$ ve S12 $\left(2662.6 \mathrm{~g} / \mathrm{m}^{2}\right)$ hatlarından verim bakımından diğer hatlara göre üstün sonuçlar elde edilmiştir. Ayrıca Arapgir biberinin morfolojik özellikleri, verim ve meyve özellikleri olarak devam eden bir çalışmanın iki yıllık ortalama sonuçları sunulmuştur. Bu bağlamda gruplar arası benzerlik dendogramı 2 farklı grup oluşturmuş ve biber örnekleri bu gruplandırmaya göre tanımlama yapılmıştır.

\section{Investigation of Promising Genotypes Selected From Arapgir Bell Pepper Population in Terms of Their Plant Characteristics}

\section{Article Info}

Received: 17.09.2020

Accepted: 30.12.2020

Online Published 30.03.2021

DOI: 10.29133 /yyutbd.793803

\section{Keywords}

Pepper (Capsicum annuum), Variety,

Genetic resources,

Selection,

Yield.

\begin{abstract}
In this study, 80\% preferred pepper cultivation in Malatya, one of the most grown vegetables in the areas which are consumed by the local people and grown in vegetable is realized with local Arapgir pepper landrace. The purpose of the study is to obtain from the starting material to develop a standard and hybrid variety by revealing lines of high purity, yield, and quality of the population. Seeds were collected from the regions where Arapgir pepper was cultivated intensively. Plants grown from these seeds were evaluated and the lines were purified by the method of "Progeny Controlled the Single Plant Selection". The lines with 20 good characteristics were determined and yield and some fruit characteristics were determined in the lines obtained at the end of two years. As a result, superior results were obtained from compared to the other lines in terms of S3 (3234.3 $\left.\mathrm{g} \mathrm{m}^{-2}\right)$, S4 (2959.7 $\left.\mathrm{g} \mathrm{m}^{-2}\right)$ and S12 (2662.6 g $\mathrm{m}^{-2}$ ) efficiency. In addition to, we present the two-year results of an ongoing study on morphological characteristics, yield and some fruit characteristics of Arapgir pepper. Average linkage cluster analysis extracted 2 different groups and pepper samples were identified according to this analysis.
\end{abstract}




\section{Giriş}

Tohum ya da tohumluk bitki yetiştiriciliği açısından en önemli unsurdur. Bitkinin verimi ya da ürün kalitesi tohumun taşıdığı özelliklerle direkt ilgilidir. Ayrıca bitki yetiştirmede uygulanan bakım işlemleri ne kadar iyi olura olsun üretimi arttırmada tohum tarafından belirlenen genetik sinırların ötesine geçemez. Yıllarca bulunduğu ekolojiye uyum sağlamak için belirli biyotik ve abiyotik stres faktörlerine karşı ayakta kalabilmiş ve devamlılığını sağlamış olan yerel popülasyonlar iyi bir materyaldir. Ülkemiz, üreticilerin gerçekleştirdiği doğal seleksiyon sonucu oluşan ve halen büyük çeşitlilik gösteren eski kültür bitkilerine ait yerel çeşitler bakımından eşsiz kaynaklara sahiptir. Tohumun tarımsal üretimde kullanılması, insanoğlunun tarıma başladığı yıl kadar eskidir. Tohum ya da tohumluk her zaman bitki yetiştiriciliği açısından en önemli unsurdur. Bir bitkinin verimi ya da ürün kalitesi tohumun taşıdığ işlemleri ne kadar iyi olura olsun üretimi arttırmada tohum tarafından belirlenen genetik sinırların ötesine geçemez. Bu anlamda yeni ve üstün bitki çeşitlerinin tarımsal üretime kazandırılması ile önemli derecede verimlilik artışı sağlamak mümkündür. Çeşit geliştirirken en iyi kaynak yerel popülasyonlardır (Arslan, 2010). İnsanoğlu süregelen yetiştiricilik sezonları boyunca tecrübeleri ve beğenileri doğrultusunda kalite özellikleri yüksek doğal seleksiyonun etkisiyle sslah ettikleri ve bulundukları yöreye adapte olmuş bir kültür bitkisine ait çeşitler, yerel çeşit ya da köy çeşidi olarak adlandırılır. Yerel gen kaynakları, çeşit ıslah çalışmalarının başarılı bir şekilde uygulanabilmesinde en önemli unsurlardan biri olan fenotipik varyasyonun esasını oluşturmaktadır (Balkaya ve ark., 2010).

Ülkemiz, birçok türün bitki genetik kaynakları ve genetik çeşitliliğinin gen merkezi konumunda olması bakımından dünyanın önemli ülkelerinden biridir (Karagöz ve ark., 2020). Yerel popülasyonlar bu açıdan zengin gen kaynakları olup, yeni genotiplerin elde edilmesinde kullanılabilecek başlangıç materyallerini oluşturmaktadır. Bu yerel çeşitlerin tüketici isteklerine uygun yeni çeşit olarak kullanılması ancak ıslah çalışmalarında kullanılması yoluyla gerçekleştirilebilir. Kayıt dışı olarak ıslah edilen yerel çeşitler, tarımı yapılan alandaki çevre koşullarına özel adaptasyonu ile karakterize edilmekte olup bunları geliştiren ve yetiştirmeye devam eden toplumların kutlama, alışkanlık, bilgi ve geleneksel kullanımları ile yakın ilişki içindedirler (Negri, 2007).

FAO 1999' a göre dünya tarımsal biyolojik çeşitliliğinin \% 75'i 20. yüzyılda kaybolmuştur. Yerel çeşitler hızla yok olmaktadır. Son senelerde yerel (ata) çeşitleri yetiştiren ve bu bağlamda genetik zenginliğimizin devamını sağlayan küçük aile işletmeleri modern çeşitlerle dada büyük alanlarda yetiştiriciliği tercih etmeye başlamışlardır. Bunun yanı sıra, artan nüfus, yoksulluk, toprak bozulmaları, çevresel değişiklikler gibi unsurlarda kültür bitkilerine ait genetik kaynaklarda erozyona yol açmıştır. Bunun yanı sıra, hızlı bir şekilde köyden kente göç olması, birçok köyde yaşlıların çoğunluğu oluşturması yerel tohumların hızla yok olmasını şiddetlendirmektedir. Ayrıca küresel ısınma nedeni ile dünyada yaşanan iklimsel ve çevresel olumsuzluklarla yerel popülasyonların güçlü bir başa çıkma kapasitesinin olduğu da bilinmektedir (Arslan, 2010).

Biber, dünyada ve ülkemizde değişik şekillerde yoğun olarak tüketilen, bahçe ve tarla sebzeciliği yanında en önemli sera sebzelerinden birisidir. Ülkemizin hemen her bölgesinde biber yetiştiriciliği yapılmaktadır. Geniş tür ve tip zenginliğine sahip olması, değişik şekillerde tüketilebilmesi ve tarıma dayalı sanayi için önemli bir hammadde olması biberi öne çıkaran özellikleridir. Biber besin içeriği bakımından oldukça yüksek değere sahiptir. 100 gram taze yeşil tatlı biberde, 29 kalori, $0.2 \mathrm{~g}$ yağ, $96.2 \mathrm{~g} \mathrm{su}, 1.1 \mathrm{~g}$ protein, $4.2 \mathrm{~g}$ karbonhidrat, $1.4 \mathrm{~g}$ selüloz bulunmaktadır (Günay, 2005). Dünyada biber üretiminde ülkemiz yıllar bazında değişiklik gösterse de ilk üçte olmayı korumakta olup, bazı yıllar Çin'den sonra ikinci sırada bazı yıllarda ise Çin ve Meksika'dan sonra üçüncü sırada yer almaktadır. Ülkemizde 2019 yılı verilerine göre; 2625669 ton biber üretimi olup bunun 378918 tonu dolmalık biber olarak yetiştirilmektedir (Tüik, 2019).

Malatya ili ve çevresindeki üreticiler, "Arapgir biberi” nin tohumunu geleneksel yöntemler kullanarak daha çok kendi tohumunu kendileri almak suretiyle biber üretimini yapmaktadır. Biberde tohum üretiminde izolasyon tekniklerine özen gösterilmediği sürece genotipler arasında heterojenite meydana gelebilmektedir. Son yıllarda Adıyaman yöresinden getirilen biber popülasyonu da yörede üretilmeye başlamış bunun yanında diğer üretimi yapılan çeşit ve popülasyonlarla Arapgir biberinin karışması, verim, meyve iriliği, şekli, rengi, aroma yönünden farklı özelliklere sahip bireylerden oluşan karışık bir popülasyon halini alması kendi gerçek özelliklerini kaybetmesi olasıdır. Bu durumda bir örnek üretim ve aynı kalitede sofralık ürün elde edilmesi kısıtlanır. 
Bir türde toplanan gen kaynaklarının karakterizasyonları yapılarak özellikleri tanımlanmadıkları sürece 1slah programlarına girmemekte, tanımlama yapılmadan 1slah programlarına alınsa bile kısa bir zaman diliminde kayba uğramaktadırlar (Balkaya ve ark., 2010). Bu nedenle gelecek nesiller için yerel çeşit çeşitliliğinin kayttlanması, ex situ ve in situ sistematik koruma durumlarının tanımlanması ve uygulanabilmesi, değişikliklerin izlenebilirliği, değişen pazar taleplerinin karşılanmasında yerel çeşit kullanımlarını artırma ve ülkemiz gıda güvenliğine katkı sağlaması bakımından ulusal yerel çeşit envanterinin hazırlanması öncelik taşımaktadır (Taş ve ark., 2017).

Ülkemizde ise biber 1slahı çalışmaları 1980'li yıllarda başlamış ve başarılı sonuçlar alınmıştır. Bu çalışmaların sonucunda birçok standart çeşit geliştirilmiştir (Sürmeli ve Erdoğan, 1985; İnan, 1988; Sürmeli ve Şimşek, 1991; Ekiz ve Kemer, 1995). Ülkemizde son yıllarda hibrit biber çeşitlerinin kullanım oranı artmış olmasına rağmen halen seleksiyon yoluyla geliştirilmiş olan çeşitlerin kullanımı oldukça yaygındır. Malatya Tarım İl Müdürlüğü verilerine göre 2019 yılında Malatya ve ilçelerinde dolmalık biber ekilen alan 5625 dekar ve buradan elde edilen üretim miktarı 11527 tondur (Tüik, 2019). Bu üretimin yaklaşık \% 80’i Arapgir biberidir. Arapgir biberi dolmalık biber çeşidi olmakla birlikte; yörede taze ya da pişirilerek tüketiminin yanında turşuluk olarak da tercih edilmektedir. Meyvelerinin özellikleri; rengi açık sarı olup, ağırlığı 80-100 gram arasında, meyve eti kalınlığı 2-2.5 $\mathrm{mm}$, tatlı ve aroması güzel, 3-4 lobludur. Piyasaya giren yeni çeşitlerin devreye girmesi ve üreticiler tarafından bu çeşitlerin tercih edilmesi ve kullanılmasıyla yerel çeşitlerin her geçen gün üretimi azalmakta ve zamanla kaybolmaktadır. Bu çalışmadaki amacımız, popülasyon halindeki "Arapgir biberi"ni saflaştırma çalışmalarına başlamak, meyve kalitesi, verimi üstün olan homojen hatları belirleyerek yerel çeşidi standart çeşit haline getirmek ya da biber islahında kullanılacak nitelikli genetik materyalin oluşturulmasıdır.

\section{Materyal ve Yöntem}

Deneme, Malatya Turgut Özal Üniversitesi Ziraat Fakültesine ait Araştırma ve Uygulama Alanında yürütülmüştür. Arapgir biberinin geniş alanlarda yetiştirildiği, Malatya'nın biber yetiştiriciliği yoğun yapılan ilçelerinden özellikle Arapgir ve köylerinden bitki, meyve özellikleri ve verim yönünden üstün değerler gösteren bitkilerin meyvelerinden alınan tohumlar, bitkisel materyali oluşturmuştur. İlk yıl 16 farklı lokasyonda her lokasyonda 10 farklı üreticiden alınan 160 hat tohumla çalışılmışıı. Üreticilerin lokasyonları Arapgir ilçesi merkez dahil olmak üzere; Alıçlı, Çakırsu, Eynir, Günyüzü, Kaynak, Kılıçlı, Paçalı, Sugeçti, Selamlı, Tarhan, Taşdibek köyleri olmakla birlikte Yazıhan ilçe merkezi ve Akyazı, Balaban ve Boztepe köyleridir. Çalışma 2016-2018 yıllarında gerçekleştirilmiş, "Döl Kontrollü Teksel Seleksiyon" yöntemi kullanılarak ilk yıl popülasyondan elit bitkiler seçilmiş ve her bitkinin tohumları bir hat oluşturacak şekilde yetiştirilmiştir. İlk yıl popülasyondan elit bitkiler seçilmiş ve her bitkinin tohumları bir hat oluşturacak şekilde yetiştirilmiş, hatlar bitki ve meyve özellikleri ile verim yönünden gözlenerek, üstün hatlardan en iyi bitkiler seçilerek kendilenmiş ve yeni hatlar oluşturulmuştur. İkinci yıl kendilenen yeni hatlar ile deneme kurulmuştur. İkinci yıl hatları arasında yine en iyileri belirlenerek hat sayısı 20'e düşürülmüss ve makalede üçüncü yıl 20 hat üzerinden deneme sonuçları sunulmuştur.

\subsection{Denemenin kurulması}

Arapgir biber tohumları torf+perlit $(1 / 2+1 / 2)$ karışımı harcın bulunduğu viyollere Mart ayının ilk haftası ekilerek fide üretimleri serada gerçekleştirilmiştir. Fideler 28 Mayıs 2018 tarihinde arazideki yerlerine $0.8 \times 0.5 \mathrm{~m}$ dikim mesafesi ile tesadüf parselleri deneme desenine göre üç tekerrürlü ve her tekerrürde yedi bitki olacak şekilde dikilmiştir. Genotiplerin morfolojik variyabilitesini belirlemek amacıyla toplam 14 farklı fenotipik özellikten yararlanılmıştır. Parsellerden hasat iriliğinde alınan yaklaşık 30 adet meyvede meyve boyu, çapı, ağırlı̆̆ı, lob sayısı ve et kalınlığı belirlenmiştir. Meyve ve bitki ölçümlerinde cetvel ve dijital kumpas kullanılmıştır. Biyomas ölçümleri yeşil yaş aksamlar kese kâğıtlarına konulup hava dolaşımlı kurutma firınında $65-70{ }^{\circ} \mathrm{C}$ 'de kurutularak (g) olarak belirlenmiştir. Verilecek gübre miktarları, deneme alanının toprak analizi sonuçlarına (Çizelge 1) göre belirlenmiş olup dekara; $12 \mathrm{~kg} \mathrm{da}^{-1} \mathrm{~N}, 5 \mathrm{~kg} \mathrm{da}^{-1} \mathrm{P}, 15 \mathrm{~kg} \mathrm{da}^{-1} \mathrm{~K}, 5 \mathrm{~kg} \mathrm{da}^{-1} \mathrm{Ca}$ ve $3 \mathrm{~kg}$ $\mathrm{da}^{-1} \mathrm{Mg}$ olacak şekilde uygulanmıştır (Şalk ve ark., 2008). 
Çizelge 1. Deneme alanında yapılan toprak analiz sonucu

\begin{tabular}{lll}
\hline & Derinlik $(0-30 \mathrm{~cm})$ & Sonuç \\
\hline Saturasyon (\%) & 55.0 & Killi Tinlı \\
pH $(1: 2,25)$ & 8.17 & Orta Alkali \\
EC (mmhos/cm) & 1.066 & \\
$\%$ Tuz & 0.04 & Tuzsuz \\
Kireç (\%) & 43.7 & Çok Yüksek \\
Organik Madde (\%) & 3.80 & Yeterli \\
Azot (\%) & 0.202 & Yüksek \\
Alınabilir Fosfor $(\mathrm{ppm})$ & 39.07 & Yüksek \\
Alınabilir Potasyum $(\mathrm{ppm})$ & 765.00 & Çok Yüksek \\
\hline
\end{tabular}

Bitkilerde incelenmiş olan özellikler: Bitkide incelenecek kriterler IBPGR (International Board for Plant Genetic Resources) tanımlamalarına (descriptor) göre belirlenmiştir.

Çizelge 2. Bitkilerde incelenmiş olan özellikler

\begin{tabular}{ll}
\hline Bitki özellikleri & Meyve özellikleri \\
\hline Bitki büyüme şekli & Meyve boyu \\
İlk çiçeklenme için geçen gün sayısı & Meyve çapıı \\
İlk meyve olgunlaşması için geçen gün sa & Meyve ağırlığı \\
Bitki yeşil aksam yaş ağırlığı & Meyve eti kalınlığı \\
Bitki yeşil aksam kuru ağırlığı & Meyve rengi \\
& Meyve odacık sayısı \\
& Meyve enine kesit şekli \\
& Meyve çiçek ucu şekli \\
& Meyve başına tohum ağırlığı \\
\hline
\end{tabular}

İncelenen özelliklerin istatistiki değerlendirmeleri için JMP 8.0 analiz paket programı kullanılmıştır. Genotipler arasındaki farklılıkların belirlenmesi için Duncan Testinden istifade edilmiştir. Ayrıca biber örneklerinin morfolojik özelliklerine göre yakınlık uzaklık ilişkilerini belirlemek için de kümeleme (cluster) analizi SAS-JMP/8 istatistik programı kullanılmıştır.

\section{Bulgular}

\subsection{Bitkilerde yapılan gözlem ve ölçümlere ait bulgular}

Biber genotipleri arasında ölçülebilen gözlem değerleri arasında geniş bir varyasyon olduğu saptanmıştır. Arapgir biber bitkisi ve meyvesine ait görseller Şekil 1'de sunulmuştur. IBPGR tanımlamalarına göre Arapgir biber bitkisinin özellikleri aşağıdaki gibidir (Çizelge 3).

Çizelge 3. Arapgir biber bitkisinin genel özellikleri

\begin{tabular}{|c|c|c|c|}
\hline \multicolumn{2}{|l|}{ Bitki özellikleri } & \multicolumn{2}{|l|}{ Meyvelerde alınan özellikler } \\
\hline Bitki büyüme şekli & dik & Meyve boyu & $74 \mathrm{~mm}$ \\
\hline İlk çiçeklenme için geçen gün sayısı & 23 gün & Meyve çapı & $48 \mathrm{~mm}$ \\
\hline İlk meyve olgunlaşması için geçen gün sayısı & 54 gün & Meyve ağırlı̆̆1 & $42 \mathrm{~g}$ \\
\hline Bitki yeşil aksam yaş ağırlığı & $2297 \mathrm{~g}$ & Meyve eti kalınlığı & $2.22 \mathrm{~mm}$ \\
\hline Bitki yeşil aksam kuru ağırlığı & $399 \mathrm{~g}$ & Meyve rengi & sar1 \\
\hline 1000 tohum ağırlı̆̆ & $11.95 \mathrm{~g}$ & Meyve odacık sayısı & 4 \\
\hline \multirow[t]{3}{*}{ Hipokotilde antosiyan oluşumu } & yok & Meyve enine kesit şekli & düz \\
\hline & & Meyve çiçek ucu şekli & içe çökmüş \\
\hline & & Meyve başına tohum ağırlığ & $0.735 \mathrm{~g}$ \\
\hline
\end{tabular}




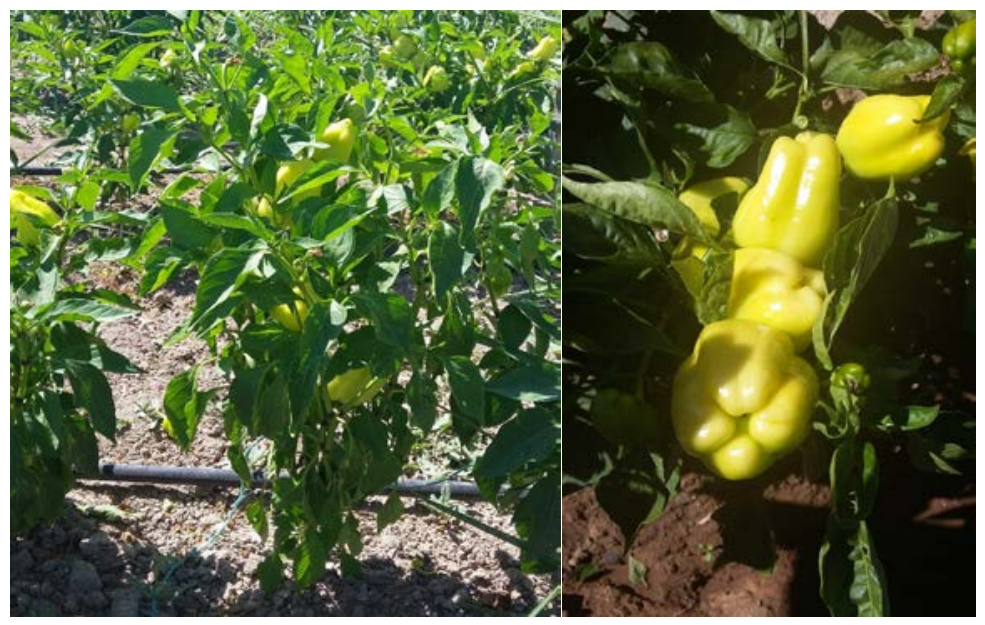

Şekil 1. Arapgir biber bitkisi ve meyvesi.

Hatlarda bitkilerde yapılan ölçüm sonuçları ve verim değerleri Çizelge 4'de sunulmuştur. Çizelge 4'deki sonuçlar değerlendirildiğinde, verim, bitki boyu, yeşil aksam yaş ve kuru ağırlık verileri istatiksel düzeyde anlamlı sonuçlar verirken gövde çapının sonuçlarında önemli farklılıklar bulunmamıştır. Bu bağlamda sırasıyla S3 $\left(3234.3 \mathrm{~g} / \mathrm{m}^{2}\right)$, S4 $\left(2959.7 \mathrm{~g} / \mathrm{m}^{2}\right), \mathrm{S} 12\left(2662.6 \mathrm{~g} / \mathrm{m}^{2}\right)$ ve S5 $\left(2387.7 \mathrm{~g} / \mathrm{m}^{2}\right)$ hatlarına ait bitkilerde en yüksek verim sonuçları elde edilmiştir. Bitkisel özelliklerde ise; bitki boyu bakımından, $\mathrm{S} 8(64.07 \mathrm{~cm}), \mathrm{S} 9(63.94 \mathrm{~cm}), \mathrm{S} 15(56.76 \mathrm{~cm})$ ve $\mathrm{S} 4(55.02 \mathrm{~cm})$ hatları; yeşil aksam yaş ağırlık, S16 (2967.3 g), S2 (2816.2 g), S20 (2683.6 g) ve S17 (2628.1 g) hatları öne çıkmıştır. Yeşil aksam kuru ağırlık bakımından ise S12 (518.33 g), S1 (491.66 g) ve S20 (468.66 g) hatları öne çıkmıştır. Gövde çapı bakımından hatları arasında fark oluşamamasına rağmen diğer bitkisel özelikleri iyi olan hatalara yakın sonuçlar elde edilmiştir.

Çizelge 4. Seçilmiş kendilenen hatlarda bitkilere ait bazı ölçüm ve verim sonuçları

\begin{tabular}{|c|c|c|c|c|c|}
\hline $\begin{array}{l}\text { Kendilenen } \\
\text { hatlar }\end{array}$ & $\begin{array}{l}\text { Bitki Boyu } \\
(\mathrm{cm})\end{array}$ & $\begin{array}{l}\text { Gövde } \\
\text { çap1 (mm) }\end{array}$ & $\begin{array}{l}\text { Yeşil aksam } \\
\text { yaş ağırlık (g) }\end{array}$ & $\begin{array}{l}\text { Yeşil aksam } \\
\text { kuru ağırlık (g) }\end{array}$ & $\begin{array}{l}\text { Verim } \\
\left(\mathrm{g} / \mathrm{m}^{2}\right)\end{array}$ \\
\hline S1 & 50.38 bcde & 16.02 & $2816.2 \mathrm{ab}$ & $491.66 \mathrm{ab}$ & 1980.2 bcde \\
\hline S2 & 49.16 bcde & 15.06 & 2352.1 bcdefg & 437.66 bcde & 2003.0 bcde \\
\hline S3 & 52.67 bcd & 17.43 & 2399.3 bcdef & 412.66 cdef & $3234.3 \mathrm{a}$ \\
\hline S4 & $55.02 \mathrm{abc}$ & 19.66 & 2328.6 bcdfgh & 407.66 def & $2959.7 \mathrm{ab}$ \\
\hline S5 & 53.25 bc & 16.49 & 2571.6 abcde & $456.66 \mathrm{bcd}$ & 2387.7 abcd \\
\hline S6 & $43.25 \mathrm{e}$ & 14.06 & $1889.6 \mathrm{gh} 1$ & 338.66 gh1 & 1350.7 de \\
\hline S7 & 50.02 bcde & 14.27 & 2032.3 fghı & 336.33 gh1 & 1763.1 bcde \\
\hline S8 & $64.07 \mathrm{a}$ & 12.98 & 1979.2 fghı & 380.10 efgh & 1497.0 cde \\
\hline S9 & $63.94 \mathrm{a}$ & 16.02 & 2140.1 defgh 1 & 379.20 efgh & 2337.5 abcd \\
\hline S10 & 51.33 bcde & 16.37 & $1777.1_{1}$ & 319.66 h1 & 1931.8 bcde \\
\hline S11 & 50.48 bcde & 16.33 & 2096.1 efghı & $352.33 \mathrm{fgh}$ & 1991.1 bcde \\
\hline S12 & 48.40 bcde & 18.28 & 2374.1 bcdefg & $518.33 \mathrm{a}$ & 2662.6 abc \\
\hline S13 & 47.60 bcde & 17.37 & $1847.3 \mathrm{~h} 1$ & 342.33 gh1 & 2353.8 abcd \\
\hline S14 & 50.48 bcde & 15.71 & 1928.3 fghı & 286.001 & 1861.9 bcde \\
\hline S15 & $56.76 \mathrm{ab}$ & 15.14 & 2205.1 cdefgh 1 & $357.10 \mathrm{fgh}$ & 1798.6 bcde \\
\hline S16 & 50.72 bcde & 14.54 & 2967.3 a & $468.66 \mathrm{abc}$ & 1485.8 cde \\
\hline S17 & 46.93 cde & 12.93 & 2628.1 abcd & 422.01 cde & 1287.2 de \\
\hline S18 & 46.33 cde & 15.69 & 2351.1 bcdefg & $391.01 \mathrm{efg}$ & 1793.3 bcde \\
\hline S19 & 45.89 cde & 13.43 & 2580.2 abcde & $493.33 \mathrm{ab}$ & 1226.9 de \\
\hline S20 & 43.29 de & 11.37 & 2683.6 abc & 392.02 efg & $997.8 \mathrm{e}$ \\
\hline prob & $0.0020 * *$ & ÖD & $0.0002 * *$ & $<0.0001^{* * *}$ & $0.0450 *$ \\
\hline
\end{tabular}

(1): Ortalamalar arasındaki farklar ayrı harflerle gösterilmiștir.

(2): ÖD: Önemli Değil; ***:p<0.001;**:p<0.01; *: $<<0.05$. 


\subsection{Meyvelerde yapılan ölçümlere ait bulgular}

Hatlarda hasat edilen meyvelerde yapılan ölçüm sonuçları ise Çizelge 5'de sunulmuştur. Çizelge 5'te meyvelere ait fiziksel özellikler bakımından incelendiğinde meyve çapı, meyve boyu ve meyve eti kalınlığı istatiksel anlamda önemli bulunmuş olup tek meyve ağırlığı analiz sonuçların göre önemsiz bulunmuştur. Meyve çapı bakımından S6 (54.64 mm), S1 (52.76 mm), S7 (52.20 mm) ve S18 (52.08 mm) hatları; meyve boyu bakımından değerlendirme yapıldığında, S8 (98.44 mm), S3 (80.79 $\mathrm{mm}), \mathrm{S} 10(79.14 \mathrm{~mm})$ ve S19 $(78.29 \mathrm{~mm})$ hatları; meyve eti kalınlığı bakımından ise S6 (2.80 mm), S8 $(2.69 \mathrm{~mm}), \mathrm{S} 13(2.41 \mathrm{~mm})$ ve S2 $(2.37 \mathrm{~mm})$ hatları diğer hatlara göre daha iyi sonuçlar vermiştir.

Çizelge 5. Seçilmiş kendilenen hatlarda meyvelere ait ölçüm sonuçları

\begin{tabular}{lllll}
\hline $\begin{array}{l}\text { Kendilenen } \\
\text { hatlar }\end{array}$ & $\begin{array}{l}\text { Meyve ağırlı̆̆ } \\
(\mathrm{g})\end{array}$ & $\begin{array}{l}\text { Meyve çap1 } \\
(\mathrm{mm})\end{array}$ & $\begin{array}{l}\text { Meyve boyu } \\
(\mathrm{mm})\end{array}$ & $\begin{array}{l}\text { Meyve eti kalınlı̆̆1 } \\
(\mathrm{mm})\end{array}$ \\
\hline S1 & 41.33 & $52.76 \mathrm{ab}$ & $66.13 \mathrm{e}$ & $2.11 \mathrm{c}$ \\
S2 & 47.27 & $51.66 \mathrm{abc}$ & $68.48 \mathrm{cde}$ & $2.37 \mathrm{bc}$ \\
S3 & 45.67 & $47.70 \mathrm{bcde}$ & $80.79 \mathrm{~b}$ & $2.36 \mathrm{bc}$ \\
S4 & 49.00 & $51.97 \mathrm{abc}$ & $74.40 \mathrm{bcde}$ & $2.10 \mathrm{c}$ \\
S5 & 45.67 & $51.42 \mathrm{abc}$ & $76.57 \mathrm{bcde}$ & $2.11 \mathrm{c}$ \\
S6 & 52.33 & $54.64 \mathrm{a}$ & $78.16 \mathrm{bcd}$ & $2.80 \mathrm{a}$ \\
S7 & 49.01 & $52.20 \mathrm{ab}$ & $76.14 \mathrm{bcde}$ & $2.32 \mathrm{bc}$ \\
S8 & 49.66 & $42.98 \mathrm{ef}$ & $98.44 \mathrm{a}$ & $2.69 \mathrm{ab}$ \\
S9 & 45.33 & $50.76 \mathrm{abc}$ & $75.34 \mathrm{bcde}$ & $2.26 \mathrm{c}$ \\
S10 & 41.00 & $43.97 \mathrm{def}$ & $79.14 \mathrm{bc}$ & $2.16 \mathrm{c}$ \\
S11 & 41.00 & $48.61 \mathrm{bcde}$ & $67.60 \mathrm{de}$ & $2.14 \mathrm{c}$ \\
S12 & 43.00 & $49.48 \mathrm{abcd}$ & $70.04 \mathrm{cde}$ & $2.24 \mathrm{c}$ \\
S13 & 42.00 & $46.27 \mathrm{bcde}$ & $74.18 \mathrm{bcde}$ & $2.41 \mathrm{abc}$ \\
S14 & 39.33 & $47.54 \mathrm{bcde}$ & $76.23 \mathrm{bcde}$ & $2.09 \mathrm{c}$ \\
S15 & 39.00 & $48.50 \mathrm{bcde}$ & $70.74 \mathrm{bcde}$ & $2.11 \mathrm{c}$ \\
S16 & 41.50 & $48.47 \mathrm{bcde}$ & $76.13 \mathrm{bcde}$ & $2.15 \mathrm{c}$ \\
S17 & 33.33 & $44.43 \mathrm{def}$ & $72.13 \mathrm{bcde}$ & $2.04 \mathrm{c}$ \\
S18 & 42.00 & $52.08 \mathrm{ab}$ & $67.04 \mathrm{e}$ & $2.04 \mathrm{c}$ \\
S19 & 40.00 & $47.75 \mathrm{bcde}$ & $78.29 \mathrm{bc}$ & $2.37 \mathrm{bc}$ \\
S20 & 25.00 & $40.11 \mathrm{f}$ & $69.59 \mathrm{cde}$ & $1.62 \mathrm{~d}$ \\
\hline prob & ÖD & $0.0006 * *$ & $0.0004 * *$ & $0.0013^{* *}$ \\
\hline
\end{tabular}

(1): Ortalamalar arasındaki farklar ayrı harflerle gösterilmiştir.

(2): ÖD: Önemli Değil; ***:p<0.001; **:p<0.01;*:p<0.05.

Kümeleme analizi sonucunda elde edilen veriler ile hazırlanan gruplar arası benzerlik dendogramı Şekil 2'de verilmiştir. Kümeleme analizi sonucunda morfolojik özellikler bakımından biber genotipleri iki farklı ana gruba ayrılmıştır. İlk ana grup kendi içerisinde iki dallanma göstermiş olup birinci dallanma (1a) S1, S2, S3, S4, S5, S9, S11, S12, S15, S18 genotiplerinden oluşurken ikinci dallanma (1b) S6, S7, S8, S10, S13, S14, genotiplerinden oluşmaktadır. Birinci grup tüm incelenen deneme materyallerinin \%80'ini kapsamaktadır. Bu grupta yer alan örnekler $43-65 \mathrm{~cm}$ arasında bitki yüksekliğine sahip olup en uzun boylu bitkiler bu grupta yer almıştır. Grup üyeleri gövde çapı, dallanma şekli, olgun meyve rengi, çiçek burnu şekli ve meyvenin enine kesiti gibi özellikler yönünden birbirlerine yakın benzerlik göstermektedir. Meyve özellikleri bakımından değerlendirildiğinde tek meyve ağırlığı, meyve çapı, meyve boyu, meyve eti kalınlığı yönünden popülasyonun en yüksek değerlerine sahiptir. Bu gruptaki genotipler genel anlamda birbirine benzerlik göstermelerine rağmen grup içerisindeki morfolojik özellikler bakımından varyasyonun göstermiştir. Birinci alt ana gruplarda yer alan S3 ve S4 genotipleri aynı grup içerisinde yer alarak benzer yakınlık göstermekte olup deneme kullanılan popülasyon içinde en yüksek meyve verimine sahip genotipler olmuştur.

İkinci ana grupta S16, S17, S19 ve S20 genotipleri yer almaktadır (Şekil 2). Bu grup incelenen tüm popülasyonun \%10’unu kapsamıştır. Bu grupta toplanan genotiplerin meyve çapı, tek meyve ağırlığı, meyve eti kalınlığı bakımından en düşük değerlere sahip olduğu tespit edilmiştir. $\mathrm{Bu}$ 
bağlamda bu grupta yer alan örneklerin meyve eti diğerlerine nazaran daha ince yapıdadır. Kümeleme analizi sonucunda S16 kodlu genotipinin birinci grup üyelerinden S1 genotipi ile agronomik ve morfolojik akrabalık derecesi bakımından birbirine en uzak genotip olduğu belirlenmiştir. İkinci ana grupta bulunan genotipler verim bakımından da birbirlerine yakın benzerlik göstermekle birlikte S20 genotipi tüm popülasyon içinde en düşük verim potansiyeline sahip olan genotip olduğu tespit edilmiştir.

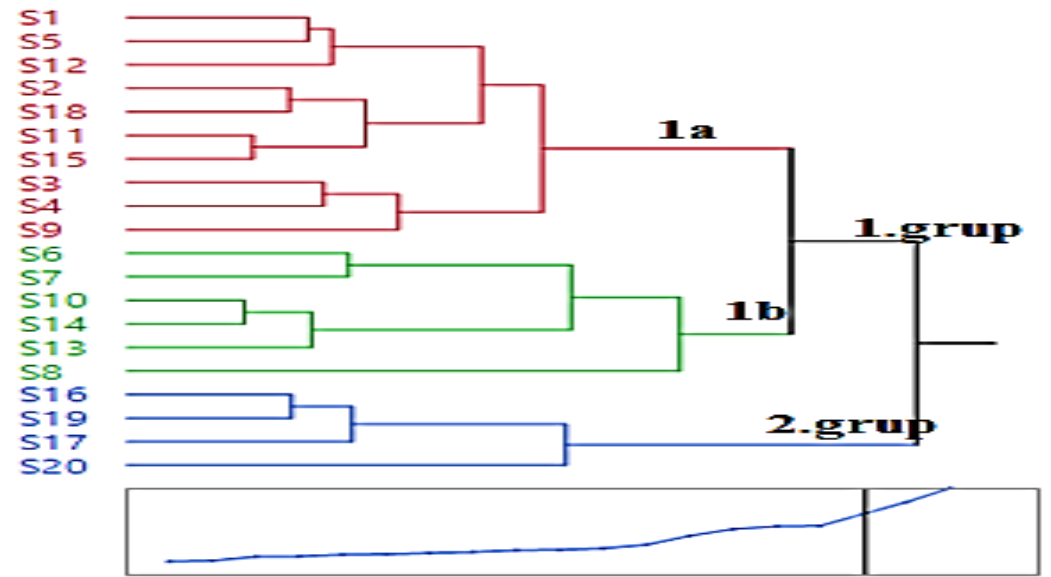

Şekil 2. Kümeleme (cluster) analizi sonucunda elde edilen veriler ile hazırlanan gruplar arası benzerlik dendogramı.

\section{Tartışma ve Sonuç}

Çalışmada, Malatya ili ve çevresinde yaygın olarak yetiştirilen populasyon ve hatlarının çeşitli bitkisel özellikler bakımından gösterdikleri varyasyonlar incelenmiştir. Ülkemizde sebzelerde çeşit geliştirmenin ilk çalışmaları, 1960'lı yıllarda tarımsal araştırma enstitülerinde başlamıştır. Bu çalışma sonucunda 1964 yılında, Ege Tarımsal Araştırma Enstitüsü tarafından Topan 374, Kemer 27 patlıcan çeşitleri ile Geçit Kuşağı Tarımsal Araştırma Enstitüsü tarafından 11B-14 biber çeşitleri ilk olarak tescil ettirilmiş̧ir. Son elli yılda yerel genetik kaynaklardan yararlanılarak yürütülen çeşit sslah programları sonucunda 15 sebze türünde 75 adet açıta tozlanan sebze çeşidi tescil edilmiştir. Günümüzde yerli standart çeşitlerin kullanım oranı oldukça azalmıştır. Buna rağmen; domateste H.2274, biberde Yağlık-28 ve Serademre-8, taze fasulyede Özayşe çeşitleri gibi bazı yerli çeşitler piyasada üreticiler tarafından talep gören çeşitlerdir (Balkaya ve Karaağaç, 2005). Bu saptamalar doğrultusunda bölgede talep gören Arapgir Biberi de yerli çeşidimiz olarak piyasada yerini bulmalıdır. $\mathrm{Bu}$ amaçla yapılan çalışmada Malatya ili ve çevresinde üretimi yapılan ve severek tüketilen, taze tüketiminin yanında kurutmalık ve turşu yapımında da değerlendirilen Arapgir biberinde verim ve meyve fiziksel özellikleri istatiksel analiz sonuçları incelenmiş olup, verim değerleri bakımından S3, S4 ve S12, bitkisel özellikler bakımından S8, S9, S4, S12, meyve özellikleri bakımından da S3, S4, $\mathrm{S} 6, \mathrm{~S} 7, \mathrm{~S} 8$ ve S7 hatlarının diğer hatlardan daha üstün gruplar olduğunu söyleyebiliriz. Bu hatların kendilenerek saflaştırmaya devam edilmesi, standart çeşit elde etmek için kullanılması ya da F1 hibrit çeşit eldesinde ebeveyn hat olarak kullanılması mümkündür.

Çalışmamıza benzer bir araştırmada morfolojik ve agronomik özelliklere göre genotipler dendrogramda 15 gruba ayrılmıştır. Kümeleme analizi sonucunda; S1, S2, S62, S3, S9, S67 ve TR69737 kodlu genotiplerin agronomik ve morfolojik akrabalık derecesi bakımından birbirine en uzak genotipler olduğunu belirlemiştir (Başak 2019). Belay ve ark. 2019, kuzey Etiyopya çalışmış oldukları 64 acı biber genotipinde çalışmada test genotipleri arasında önemli \%79 oranında genetik çeşitlilik olduğunu ve sslah çalışmaları için önemli firsatlar oluşturabileceğini bildirmişlerdir. Patel ve ark., (2017)'nın 72 patlıcan genotipinde genetik çeşitliliğin ortaya konması için yürüttükleri çalışmada önemli verimli kraterlerine ulaşmışlardır. Bu bağlamda çalışmamıza benzer şekilde ülkemizde; üniversiteler ve araştırma enstitüleri tarafından da yerel sebze popülasyonlarının değerlendirmesine yönelik çok sayıda çalışma yapılmıştır. 
Yerel genetik kaynaklarımızın toplanması ve özelliklerinin incelenmesine yönelik çalışmalar Kabakgillerde (Sar1 ve ark., 2005; Yetişir ve ark., 2008; Karipcin ve ark., 2010; Şensoy ve Şahin, 2012;), patlıcangillerde (Sürmeli ve ark., 2007; Karaağaç ve Balkaya, 2009; Oğuz ve ark., 2014; Sönmez ve ark., 2015; Keleş ve ark., 2016, Cakir ve ark., 2017), lahanagillerde (Balkaya ve ark., 2005), fasulyede (Madakbaş ve ark., 2006; Erdinç ve ark., 2013; Karaağaç ve ark., 2014), Fidan ve ark., 2016), soğanda (Hancı ve Gökçe, 2016) ve havuçta (Kirac1, 2013; Ipek ve ark., 2016) çalışmışlardır. Ancak genelde bu tür çalışmaların gen bankalarından materyal temin edilmesi şeklinde gerçekleştirilmesinden dolayı, materyaller toplandıkları coğrafik ve ekolojik koşulların dışındaki şartlarda da incelenebilmektedir. Bu sebeple morfolojik ve agronomik karakterizasyon çalışmalarında materyallerin daha sağlıklı bir şekilde değerlendirilebilmesi için öncelikle toplanıldı̆̆ ekolojik koşullarda veya benzer koşullarda tanımlanmasının yapılması daha uygun olabilir (Başak, 2019; Öntürk ve Çürük; 2019). Binbir (2010), 26 biber genotipini 54 morfolojik özellik bakımından karakterize etmiş, genotiplerin biber tiplerinin birçoğunu içermesinden dolayı geniş varyasyon gösterdiğini bildirmiş̧ir. Çalışmada incelenen populasyonların biber tiplerinin gruplar arası benzerlik dendogramında 3 farklı grup oluşturduğunu bildirmiştir. Islah çalışmalarında kullanılacak materyallerin yüksek varyasyon göstermesi istenilen bir durumdur (Gözen, 2008; Bozokalfa ve Eşiyok, 2010). Bulgularımızla benzer şekilde bir çok araştırmacı da tespit edilen varyasyonun büyük bir kısmının meyve ile ilgili agronomik ve morfolojik özelliklerden kaynaklandığını bildirmiş̧ir (Mutlu ve ark., 2009; Bozokalfa ve Eşiyok, 2010). Meyve özellikleri açısından yüksek varyabilitenin oluşmasında, biberde yüksek oranda görülen yabancı tozlanmanın etkisi önemlidir.

Çalışmada kullanılan materyallerin bir kısmı da çeşit ıslah çalışmalarında değerlendirilmiştir. $\mathrm{Bu}$ bağlamda kümeleme analiz sonuçlarını da dikkate alırsak 1. grup popülasyondan seçilecek olan genotiplerin ıslah çalışmaları için kullanılabileceği görülmektedir. Sonuç olarak önerimiz; farklı özelliklerdeki yerel çeşitlerin, coğrafi işaret tescil çalışmalarının yaygınlaştırılarak tanınırlıklarının arttırılması gerekmektedir.

\section{Teşekkür}

$\mathrm{Bu}$ proje, İnönü Üniversitesi Bilimsel Araştırma Projeleri Koordinasyon Birimi tarafından 2016/54 nolu Araştırma Projesi olarak desteklenmiştir. Projenin yürütülmesinde destek olan İnönü Üniversitesi Bilimsel Araştırma Projeleri Koordinasyon Birimine ve İnönü Üniversitesi Rektörlüğüne teşekkür ederiz.

\section{Kaynakça}

Arslan, N. (2010). Uluslararası biyoçeşitlilik yılı münasebetiyle tarımsal biyoçeşitlilik ve yerel çeşitlerin/ekotiplerin önemi. Ziraat Mühendisliği, (354), 4-9.

Balkaya, A., \& Karaağaç, O. (2005). Vegetable genetic resources of Turkey. J. of Vegetable Science, 11 (4), 81-102.

Balkaya, A., Özbakır, M., \& Karaağaç, O. (2010). Karadeniz bölgesi'nden toplanan bal kabağı (Cucurbita moschata Duch.) popülasyonlarındaki meyve özelliklerinin karakterizasyonu ve varyasyonun değerlendirilmesi. Tarım Bilimleri Dergisi, 16, 17-25.

Balkaya, A., Yanmaz, R., Apaydin, A., \& Kar, H. (2005). Morphological characterisation of white head cabbage (Brassica oleracea var. capitata subvar. alba) genotypes in Turkey. New Zealand Journal of Crop and Horticultural Science, 33 (4), 333-341.

Başak, H., (2019). Kırşehir yerel sivri biber (Capsicum annuum L. var. longum) populasyonlarının agronomik ve morfolojik karakterizasyonu. KSÜ Tarım ve Doğa Derg., 22(2), 202-216.

Belay, F., Abate, B., \& Tsehaye, Y. (2019). Genetic diversity studies for morphological traits of hot pepper (Capsicum annuum L.) genotypes in Central Zone of Tigray Region, Northern Ethiopia. African Journal of Agricultural Research, 14 (33), 1674-1684.

Binbir, S., (2010). Bazı yerel biber (Capsicum annuum L.) Popülasyonlarında karakterizasyon çalışmaları. Adnan Menderes Üniversitesi, Fen Bilimleri Enstitüsü, Aydın.

Bozokalfa, MK., \& Eşiyok, D. (2010). Biber (Capsicum annuum L.) aksesyonlarında genetik çeşitliliğin agronomik özellikler ile belirlenmesi. E.Ü. Ziraat Fak. Derg., 47(2), 123-134. 
Cakir, Z., Balkaya, A., Saribas, S., \& Kandemir, D. (2017). The morphological diversity and fruit characterization of Turkish eggplant (Solanum melongena L.) Populations. Ekin Journal of Breeding and Genetic, 3 (2), 34-44.

Ekiz, H., \& Kemer, M., (1995). Breeding of Demre pepper. IX th Meeting on Genetics and Breeding on Capsicum and Eggplant. Budapest, Hungary.

Erdinç, Ç., Türkmen, Ö., \& Şensoy, S. (2013). Türkiye'nin bazı fasulye genotiplerinin çeşitli bitkisel özelliklerinin belirlenmesi. Yüzüncü Yıl Üniversitesi Tarım Bilimleri Dergisi, 23 (2): 112-125.

Fidan, S., Lökoğlu, N., \& Sarıçam, Ş. (2016). Ülkesel ıspanak genetik kaynaklarının karakterizasyonu

Gözen, V., (2008). Hiyarda (Cucumis sativus L.) örtüaltı yetiştiriciliğine uygun hibrit çeşit ıslahında morfolojik karakterizasyon, hibrit kombinasyonlart ile hibrit tohum verim ve kalitesinin belirlenmesi. Ankara Üniversitesi, Fen Bilimleri Enstitüsü, Bahçe Bitkileri Anabilim Dalı, Doktora Tezi, 185 s, Ankara.

Günay, A., (2005). Sebze Yetiştiriciliği i. Cilt 1.İzmir.

Hanc1, F., \& Gökçe, A.F. (2016). Molecular characterization of Turkish onion germplasm using ssr markers. Czech J. Genet. Plant Breed, 52 (2), 71-76.

Ipek, A., Türkmen, Ö., Fidan, S., Ipek, M., \& Karci, H. (2016). Genetic variation within the purple carrot population grown in ereğli district in Turkey. Turkish Journal of Agriculture and Forestry, 40 (4), 570-576.

İnan, Y., (1988). Çarliston Biber Islahı. TAGEM Sonuç Raporu, Yalova, s.15.

Karaağaç, O., \& Balkaya, A. (2009). Bafra kırmızı biber popülasyonları [Capsicum annuum L. var. conoides (Mill.) Irish] tanımlanması ve mevcut varyasyonun değerlendirilmesi. Anadolu Tarım Bilimleri Dergisi, 25 (1), 10-20.

Karaağaç, O., Kar, H., Özer, M., \& Doğru, Ş. (2014). Lahana 1slahı Programları için nitelikli genitörlerin geliştirilmesi ve tohum teknolojisi projesi. TAGEM-BBSS-10-17 No.Lu Proje Ara Sonuç Raporu.

Karagöz, A., Tan A., Özbek K., Yıldız A., Keskin E., Bilgin A., Aykas L., Deniz D. \& Odası, Z. M. (2020). Tarımda Bitki Genetik Kaynakları Alanında Mevcut Durum ve Gelecek Türkiye Ziraat Mühendisliği IX. Teknik Kongresi Bildiriler Kitab1-1 s. 257-281.

Karipcin, Z., Sar1, N., \& Kirnak, H. (2010, September). Effects of drought on yield and pomological features of wild and domestic Turkish watermelon genotypes. IV International Symposium on Cucurbits, Changsha, Hunan (China).

Keleş, D., Rastgeldi, U., Karipçin, Z., Karagül, S., Soylu, M. K., Çömlekçioğlu, N., \& Büyükalaca, S. (2016). Seleksiyon yoluyla Şanlıurfa biber 1slahı. Alatarım,15 (1), 39-44.

Kiracı, S. (2013). Konya ve yöresinde üstün teknolojik özelliklere sahip mor havuç tiplerinin seleksiyonu. Doktora Tezi, Süleyman Demirel Üniversitesi, Isparta, Türkiye.

Madakbaş, S.Y., Özçelik, H., \& Ergin, M. (2006). Çarşamba Ovası'nda bodur taze fasulye popülasyonlarından belirlenmiş olan hatlar arasındaki farklılıkların belirlenmesi. Harran Üniversitesi Ziraat Fakültesi Dergisi, 10 (3/4), 71-77.

Mutlu, S., Haytaoğlu, M.A., Kır, A., \& İçer, B. (2009). Ulusal Gen Bankası Biber (Capsicum Annuum L.) Materyalinde Morfolojik Karakterizasyon. Anadolu: Ege Tarımsal Araştırma Enstitüsü Dergisi (J. of AARI), 19 (1), 63-91.

Negri, V. (2007). Towards a more comprehensive definition of "landrace" than currently published. Report of a Task Force on On-farm Conservation and Management, Second Meeting, 19-20 June 2006, Stegelitz, Germany. 20 pp. Bioversity International, Rome, Italy.

Oğuz, A., Gözen, V., Kabaş, A., Zengin, S., Sönmez, K., \& Ellialtıŏglu, Ş. (2014). Determination of relationship between some turkish local tomato genotypes by using phenotypic characterization. Derim, 31 (1), 25-34.

Öntürk, G, \& Çürük, S. (2019). Hatay'ın Farklı İlçelerinde Yetiştirilen Biber Köy Popülasyonlarında Bitki ve Meyve Özellikleri. Yüzüncü Yıl Üniversitesi Tarım Bil. Dergisi, 29 (4) , 689-701.

Patel, V. K., Singh, U., Goswami, A., Tiwari, S. K., \& Singh, M. (2017). Genetic variability, interrelationships and path analysis for yield attributes in eggplant. Environ. Ecol, 35(2A), 877-880.

Sarı, N., Solmaz, I., Yetisir, H., \& Unlu, H. (2005, Eylül). Watermelon genetic resources in turkey and their characteristics. III International Symposium on Cucurbits, 
Sönmez, K., Oğuz., A., Özdamar, K., \& Ellialtıŏlu, Ş. (2015). Bazı yerel sofralık domates genotiplerinin morfolojik ve fenolojik olarak akrabalık derecelerinin belirlenmesi. Yüzüncü Yll Üniversitesi Tarım Bilimleri Dergisi, 25 (1), 24-40.

Sürmeli, N., \& Erdoğan, S., (1985). Yağlık (salçalık) biber 1slahı. Bahçe Dergisi, 14 (1-2), 31-35. Yalova.

Sürmeli, N., \& Şimşek, G., (1991). Çorbacı biber 1slahı. Yalova Bahçe Kültürleri Merkez Araştırma Enstitüsü Dergisi, 20 (1-2), 3-8.

Sürmeli, N., Beşirli, G., Başay, S., Kaynaş, K., Erdoğan, S., Sönmez, İ., \& Göçmen, M. (2007). Yeni bir biber çeşidi "Sürmeli Biberi”". Bahçe, 36 (1), 61-75.

Şalk, A., Arın, L., Deveci, M. \& Polat, S. (2008). Özel Sebzecilik; Tekirdăg, Turkey: p. 485.

Şensoy, S., \& Şahin, U. (2012). Farklı Sthke yerel kavun genotipleri arasındaki genetik ilişkiler. Yüzüncü Yıl Üniversitesi Tarım Bilimleri Dergisi, 22 (3), 147-154.

Taş, N., Kırcalıŏlu, G., Kırcı, K. K., \& Özer, U. (2017). Türkiye yerel çeşit genetik kaynaklarının muhafazas1. Turkish Journal of Scientific Reviews, 10(1), 48-52.

Tüik, (2019). http://www.tuik.gov.tr/PreTablo.do?alt id=1001. Erişim Tarihi:25.05.2020.

Yetişir, H., Şakar, M., \& Serçe, S. (2008). Collection and morphological characterization of Lagenaria siceraria germplasm from the mediterranean region of turkey. Genetic Resources and Crop Evolution, 55 (8), 1257-1266. 